\title{
Lung function predicts lung cancer risk in smokers: a tool for targeting screening
} programmes

\author{
E. Calabrò*, G. Randi ${ }^{\#,}$, C. La Vecchia ${ }^{\#,}$, N. Sverzellati ${ }^{+}$, A. Marchianò̀ ${ }^{\S}$, M. Villani ${ }^{f}$, \\ M. Zompatori**, R. Cassandro ${ }^{\# \#}$, S. Harari ${ }^{\# \#}$ and U. Pastorino*
}

ABSTRACT: The relationship between smoking, lung cancer and airflow obstruction is recognised but it is unclear whether the presence of minimal lung function damage constitutes an independent risk factor for the development of lung cancer.

In order to identify those individuals at higher risk of lung cancer on the basis of functional impairment, we evaluated baseline pulmonary function tests of 3,806 heavy smokers undergoing annual chest computed tomography screening, and compared the forced expiratory volume in $1 \mathrm{~s}$ (FEV 1 ) \% predicted of 57 lung cancer cases and that of 3,749 subjects without cancer.

We obtained odds ratios (ORs) of lung cancer and the corresponding $95 \%$ confidence intervals (Cls) using unconditional logistic regression, adjusting for age, sex, study and smoking variables. Compared with subjects with FEV $1 \geqslant 90 \%$ pred, the OR of lung cancer was 2.45 (95\% Cl 1.39-4.33) for subjects with $\mathrm{FEV}_{1}<90 \%$ pred and $2.90(95 \% \mathrm{Cl} 1.34-6.27)$ for subjects with $\mathrm{FEV}_{1}<\mathbf{7 0} \%$ pred.

These data show that even a relatively small reduction in FEV $1 \%$ pred is a significant predictor of increased lung cancer risk. Test screening for lung cancer using airflow obstruction with FEV 1 $<\mathbf{9 0 \%}$ is a strategy worth future consideration.

KEYWORDS: Lung cancer risk, lung damage, lung function, spiral computed tomography screening

$\mathbf{T}$ he relationship between smoking, lung cancer and airflow obstruction is well recognised [1]. However, it is unclear whether the presence of airflow obstruction constitutes a significant risk factor for development of lung cancer, independently from smoking [2].

Several studies have suggested that airway obstruction, based on forced expiratory volume in $1 \mathrm{~s}$ (FEV1) reduction, increases lung cancer risk [3-5]. In particular airflow obstruction can be considered as a surrogate marker of carcinogenic exposure of the airways to cigarette smoke. Therefore, it is reasonable to investigate whether individual predisposition to lung cancer as well as the clinical and pathological features of cancer arising in smokers differs according to the degree of respiratory failure [6-8].

The aim of the present study is to identify in a population of heavy smokers, recruited in prospective screening trials with annual spiral computed tomography $(\mathrm{CT})$, those individuals with higher lung cancer risk on the basis of functional damage, and to establish whether a cut-off value of lung obstruction can be assumed as a discriminating parameter for early detection lung cancer trials.

\section{MATERIALS AND METHODS}

We examined 3,806 subjects enrolled in an early detection lung cancer trial between June 2000 and April 2008. Data were collected from two Italian cohort studies that found a total of 57 cases of lung cancer screened during the observation period. The first pilot study [9] detected 36 cases of lung cancer during the 5 yrs of follow-up, and the second randomised study, the Multicentric Italian Lung Detection (MILD) project, detected 21 cases of lung cancer during the first 2 yrs of follow-up. Both trials included subjects aged 50-75 yrs, current or former smokers (having quit $<10$ yrs before the inclusion) of $\geqslant 20$ pack-yrs with no history of cancer within the prior 5 yrs. In the MILD trial, individuals were randomised in two groups: a control group which underwent a programme of primary prevention with pulmonary function test evaluation and blood sample collection, and an early detection group where periodic spiral CT is performed with primary prevention, pulmonary function evaluation and blood sample collection.
AFFILIATIONS

Divisions of *Thoracic Surgery,

${ }^{\S}$ Radiology, Fondazione IRCCS Istituto Nazionale dei Tumori,

\#Istituto di Statistica Medica e Biometria "Giulio A. Maccacaro", Università degli Studi di Milano,

"Mario Negri Institute,

fUnità Operativa Pneumologica

Ospedale San Carlo Borromeo,

\#\#Unità di Pneumologia e Terapia

Semi-Intensiva Respiratoria,

Ospedale San Giuseppe AFAR, Milan,

+Dept of Clinical Sciences, University

of Parma, Parma, and

**University of Bologna, Radiology,

Policlinico S. Orsola Malpighi

Bologna, Bologna, Italy.

CORRESPONDENCE

U. Pastorino

Division of Thoracic Surgery

Fondazione IRCCS Istituto Nazionale dei Tumori

Via G. Venezian 1

20133 Milan

Italy

E-mail: ugo.pastorino@

istitutotumori.mi.it

Received:

March 262009

Accepted after revision:

June 242009

First published online:

Aug 132009 
The early detection group is further randomised in two arms: yearly low-dose CT versus CT every 2 yrs.

The population of volunteers was recruited among respondents to advertisements and articles published in the lay press and from television broadcasts. All volunteers were assessed for their eligibility and asked to sign a consent form, including a detailed information sheet, to participate in the study. The trials were approved by the Institutional Review Board and by the Ethics Committees of the centres taking part in the project.

Participants were asked in advance to allow a couple of hours for completion of the questionnaire, physical examination, blood sampling, lung function test and spiral CT. The questionnaire included detailed information on smoking history and the presence of respiratory symptoms and previous treatment of selected diseases including cancer, physician-diagnosed chronic bronchitis, emphysema or asthma. We considered participants to be current smokers if they reported the use of cigarettes, cigars or pipes at the time of the survey, and to be former smokers if they reported any previous use of cigarettes, cigars or pipes, but no use in the last year. Information about attempts and assistance to stop smoking was also reported.

Forced vital capacity (FVC) and FEV1 were measured at baseline in all study participants by using an electronic spirometer that utilises a brass Fleisch type pneumotachometer (PDS Research UK Ltd, Kent, UK) connected to a computer for the analysis of data according to the recommendations of the American Thoracic Society and the European Respiratory Society of 2005 [10]. For each session a 3-L syringe was used to calibrate spirometer equipment. We calculated FEV1 \% predicted and assessed the risk of lung cancer for three different levels of FEV1 \% pred: $<70 \%, 70-89 \%$ and $\geqslant 90 \%$. According to the Global Initiative for Chronic Obstructive Lung Disease (GOLD) staging, we considered chronic obstructive pulmonary disease (COPD) subjects those with a FEV1/ FVC ratio $<70 \%$ [11]. Furthermore, in order to adjust for potential age-related modifying effect, we used different FEV1/FVC ratio thresholds [12-14] in subsequent age groups, i.e. $<75 \%<60 \mathrm{yrs}$ of age, $<70 \%$ at $60-69 \mathrm{yrs}$ of age and $<65 \%$ at 70 yrs of age.

\section{Analysis}

We compared the 57 lung cancer patients with 3,749 subjects without cancer. We computed the odds ratios (OR) of lung cancer, as estimators of relative risks (with the corresponding $95 \%$ confidence intervals $(\mathrm{CI})$ ) for several variables related to functional lung damage, by unconditional multiple logistic regression equations [15], including terms for sex, age and study. Further adjustment for smoking status (current or former smokers), number of cigarettes and duration of smoking habits was also applied. Since the effect of dose and duration is substantially different in the process of lung carcinogenesis [16] we adjusted the dose and duration separately. To better understand the relationship between FEV1 \% pred and the risk of lung cancer, we applied receiver operating characteristic (ROC) curves to find the best sensitivity and specificity cut-off value of FEV1\% pred. We also considered different standardisation of FEV1 and we made a comparison between FEV1 \% pred, FEV1/height ${ }^{2}$ and FEV1/height ${ }^{3}$ as suggested by MILLER et al. [17]. We performed sub-group analyses, separating individuals by sex, smoking status, tumour, node metastasis (TNM) stage and cancer histology. We assessed the significance of the interactions for the combined effect of FEV1\% pred with sex and smoking status by comparing the difference between the deviances of the models with and without the term of interest to the Chi-squared distribution with one degree of freedom. Attributable risk was calculated according to BRUZZI et al. [18].

\section{RESULTS}

Table 1 shows the distribution of 57 lung cancer cases and 3,749 controls according to selected demographic and lifestyle characteristics. Most cases and controls were male $(78.9 \%$ versus $68.1 \%$ ), and all cases were older than controls ( $22.8 \%$ versus $13.9 \%$ being 65 yrs old or older). Cases and controls did not differ by smoking status $(82.5 \%$ versus $74.7 \%$ of former smokers, respectively), but cases reported higher consumption of cigarettes $\left(57.9 \%\right.$ versus $26.6 \%$ reporting $\geqslant 30$ cigarettes $\cdot$ day $^{-1}$, respectively) and longer duration of smoking ( $66.7 \%$ versus $40.9 \%$ reporting $\geqslant 40 \mathrm{yrs}$ ). As a consequence, the number of pack-yrs was much higher among cases than controls $(73.7 \%$ versus $30.7 \%$ reporting $\geqslant 45$ pack-yrs).

Table 2 shows the distribution of cases and controls according to COPD status and levels of FEV1 \% pred, and the corresponding ORs. After adjustment for age, sex, study and smoking

\begin{tabular}{|c|c|c|}
\hline Characteristics & Lung cancer cases & Controls \\
\hline \multicolumn{3}{|l|}{ Study } \\
\hline Pilot study & $36(63.2)$ & 834 (22.2) \\
\hline MILD study & $21(36.8)$ & $2915(77.8)$ \\
\hline \multicolumn{3}{|l|}{ Sex } \\
\hline Male & $45(78.9)$ & $2554(68.1)$ \\
\hline Female & $12(21.1)$ & $1195(31.9)$ \\
\hline \multicolumn{3}{|l|}{ Age yrs } \\
\hline$<55$ & $11(19.3)$ & $1295(34.5)$ \\
\hline $55-64$ & $33(57.9)$ & $1934(51.6)$ \\
\hline$\geqslant 65$ & $13(22.8)$ & $520(13.9)$ \\
\hline \multicolumn{3}{|l|}{ Smoking status } \\
\hline Current & $47(82.5)$ & $2798(74.7)$ \\
\hline Former & $10(17.5)$ & $949(25.3)$ \\
\hline \multicolumn{3}{|c|}{ Number of cigarettes } \\
\hline$<20$ & $5(8.8)$ & $877(23.4)$ \\
\hline $20-24$ & $15(26.3)$ & $1580(42.1)$ \\
\hline $25-29$ & $4(7.0)$ & $293(7.8)$ \\
\hline$\geqslant 30$ & $33(57.9)$ & $999(26.6)$ \\
\hline \multicolumn{3}{|c|}{ Duration of smoking yrs } \\
\hline$<30$ & $2(3.5)$ & 569 (15.2) \\
\hline $30-34$ & $8(14.0)$ & $845(22.6)$ \\
\hline $35-39$ & $9(15.8)$ & $801(21.4)$ \\
\hline$\geqslant 40$ & $38(66.7)$ & $1532(40.9)$ \\
\hline \multicolumn{3}{|c|}{ Pack-yrs of smoking } \\
\hline$<35$ & $6(10.5)$ & $1568(41.9)$ \\
\hline $35-44$ & $9(15.8)$ & $1025(27.4)$ \\
\hline$\geqslant 45$ & $42(73.7)$ & $1151(30.7)$ \\
\hline
\end{tabular}

Data are presented as n (\%). MILD: Multicentric Italian Lung Detection. 
variables, the OR of lung cancer was 1.23 (95\% CI 0.68-2.25) for COPD subjects compared with non-COPD subjects, when considering the cut-off level of $70 \%$ for the $\mathrm{FEV} 1 / \mathrm{FVC}$ ratio, and the risk estimate did not materially change when we considered age-group specific cut-off levels of the FEV1/FVC ratio $(\mathrm{OR}=1.46)$. The $\mathrm{OR}$ of lung cancer was 2.45 (95\% CI 1.39 4.33) for subjects with FEV1 $<90 \%$ pred compared with subjects with $\mathrm{FEV} 1 \geqslant 90 \%$ pred. The risk increased with finer stratification of the levels of FEV1 \% pred, and the OR was $2.90(95 \% \mathrm{CI}$ 1.34-6.27) for FEV1 $<70 \%$ pred compared with FEV1 $\geqslant 90 \%$ pred. After stratification according to FEV1 \% pred and COPD status, the OR was 2.56 (95\% CI 1.29-5.07) for COPD subjects with FEV1 <90\% pred and 2.36 (95\% CI 1.23-4.52) for nonCOPD subjects with FEV1 $<90 \%$ pred compared with patients with FEV1 $\geqslant 90 \%$ pred. When we adopted different thresholds of FEV1/FVC ratio in subsequent age groups, the results were not materially modified and the OR was 2.67 for subjects with FEV1 $<90 \%$ pred and COPD and OR was 2.15 for subjects with $\mathrm{FEV} 1<90 \%$ pred without COPD.

Figure 1 shows the ROC curve plotting the accuracy of FEV1\% pred in predicting lung cancer. A cut-off level of $90 \%$ of FEV1 $\%$ pred corresponded to a sensitivity of $63.2 \%$ (95\% CI $50.6-$ $75.7)$ and a specificity of $70.5 \%$ (95\% CI 69.0-71.9). A cut-off level of $85 \%$ of FEV1 \% pred corresponded to a sensitivity of
$52.6 \%(95 \%$ CI $39.7-65.6)$ and a specificity of $79.1 \%(95 \%$ CI 77.8-80.4), and a cut-off level of $95 \%$ of FEV1 \% pred corresponded to a sensitivity of $73.7 \%$ (95\% CI 63.3-85.1) and a specificity of $59.0 \%$ (95\% CI 57.5-60.6), thus providing a worse compromise between sensitivity and specificity. The area under the curve was 0.70 using FEV1 \% pred, and was 0.68 using both FEV1/height ${ }^{2}$ and FEV1/height ${ }^{3}$.

Table 3 shows the OR of lung cancer stratified for sex and smoking status, and according to stage and histology. The risk of lung cancer for FEV1 $<90 \%$ pred was higher among females than males, and among former than current smokers, but the interactions between FEV1 \% pred and sex or smoking status were not statistically significant. When considering the ORs according to TNM stage, the risk of lung cancer was similar for stage I lung cancer $(\mathrm{OR}=2.23)$ and for stage II, III or IV $(\mathrm{OR}=2.45)$. However, the risk of lung cancer for FEV1 $<90 \%$ pred was significantly different according to histology, the OR being 1.46 (95\% CI 0.75-2.84) for adenocarcinomas and 12.29 (95\% CI 2.75-55.05) for squamous cancer and other cell types.

\section{DISCUSSION}

The present study provides definite evidence and more accurate quantification than previously available [3-8] that lung function impairment represents a significant risk of

\section{TABLE 2}

Distribution of 57 cases of lung cancer and 3,749 controls according to lung function measures and corresponding OR with $95 \% \mathrm{Cl}$

\begin{tabular}{|c|c|c|c|c|}
\hline Characteristics & $\begin{array}{c}\text { Lung cancer } \\
\text { cases }\end{array}$ & Controls & OR $(95 \% \mathrm{Cl})^{\#}$ & OR $(95 \% \mathrm{Cl})$ \\
\hline \multicolumn{5}{|l|}{$\mathrm{COPD}^{+, \S}$} \\
\hline Negative & 39 (69.6) & $2910(77.6)$ & 1.00 & 1.00 \\
\hline Positive & $17(30.4)$ & $839(22.4)$ & $1.48(0.82-2.67)$ & $1.23(0.68-2.25)$ \\
\hline \multicolumn{5}{|l|}{$\mathrm{COPD}^{\S . f}$} \\
\hline Negative & $30(53.6)$ & $2390(63.8)$ & 1.00 & 1.00 \\
\hline Positive & $26(46.4)$ & $1359(36.2)$ & $1.68(0.99-2.88)$ & $1.46(0.85-2.52)$ \\
\hline \multicolumn{5}{|l|}{ FEV $_{1} \%$ pred } \\
\hline$\geqslant 90$ & $21(36.8)$ & $2640(70.5)$ & 1.00 & 1.00 \\
\hline$<90$ & $36(63.2)$ & 1107 (29.5) & $2.94(1.67-5.16)$ & $2.45(1.39-4.33)$ \\
\hline 70-89 & $24(42.1)$ & 849 (22.7) & $2.72(1.48-4.97)$ & $2.29(1.24-4.23)$ \\
\hline$<70$ & $12(21.1)$ & $258(6.9)$ & $3.64(1.70-7.81)$ & $2.90(1.34-6.27)$ \\
\hline Chi trend ( $p$-value) & & & $14.5(0.0001)$ & $9.45(0.0021)$ \\
\hline \multicolumn{5}{|l|}{$\mathrm{FEV}_{1} \%$ pred and $\mathrm{COPD}^{+, \S}$} \\
\hline $\mathrm{FEV}_{1} \geqslant 90 \%$ pred & $21(36.8)$ & 2640 (70.5) & 1.00 & 1.00 \\
\hline FEV $1<90 \%$ pred without COPD & $19(33.3)$ & $582(15.5)$ & $2.75(1.44-5.25)$ & $2.36(1.23-4.52)$ \\
\hline FEV $1<90 \%$ pred with COPD & $17(29.8)$ & $525(14.0)$ & $3.19(1.63-6.23)$ & $2.56(1.29-5.07)$ \\
\hline Chi trend ( $p$-value) & & & $13.4(0.0003)$ & $8.4(0.0037)$ \\
\hline \multicolumn{5}{|l|}{$\mathrm{FEV}_{1} \%$ pred and COPD ${ }^{\S, f}$} \\
\hline FEV $1 \geqslant 90 \%$ pred & $21(36.8)$ & $2640(70.5)$ & 1.00 & 1.00 \\
\hline FEV $1<90 \%$ pred without COPD & $14(24.6)$ & $450(12.0)$ & $2.51(1.24-5.09)$ & $2.15(1.05-4.40)$ \\
\hline FEV $1<90 \%$ pred with COPD & $22(38.6)$ & $657(17.5)$ & $3.28(1.77-6.09)$ & $2.67(1.42-5.01)$ \\
\hline Chi trend ( $p$-value) & & & $14.8(0.0001)$ & $9.6(0.0019)$ \\
\hline
\end{tabular}

Data are presented as $n(\%)$, unless otherwise stated. COPD: chronic obstructive pulmonary disease; FEV1: forced expiratory volume in 1 s; \% pred: \% predicted. \#: obtained from unconditional logistic regression after adjustment for age, sex and study; ${ }^{\prime}$ : obtained from unconditional logistic regression after adjustment for age, sex, study, smoking status, duration of smoking and number of cigarettes; ${ }^{+}$. COPD cases had FEV1/forced vital capacity (FVC) index $<70 \%$ for all subjects; ${ }^{\S}$ : the sum does not add up to the total because of missing values; ${ }^{f}$ : COPD cases had FEV $1 /$ FVC index index $<75 \%$ for subjects of age $<60$ yrs, $<70 \%$ for subjects aged $60-69$ yrs and $<65 \%$ for subjects aged $\geqslant 70 \mathrm{yrs}$. 


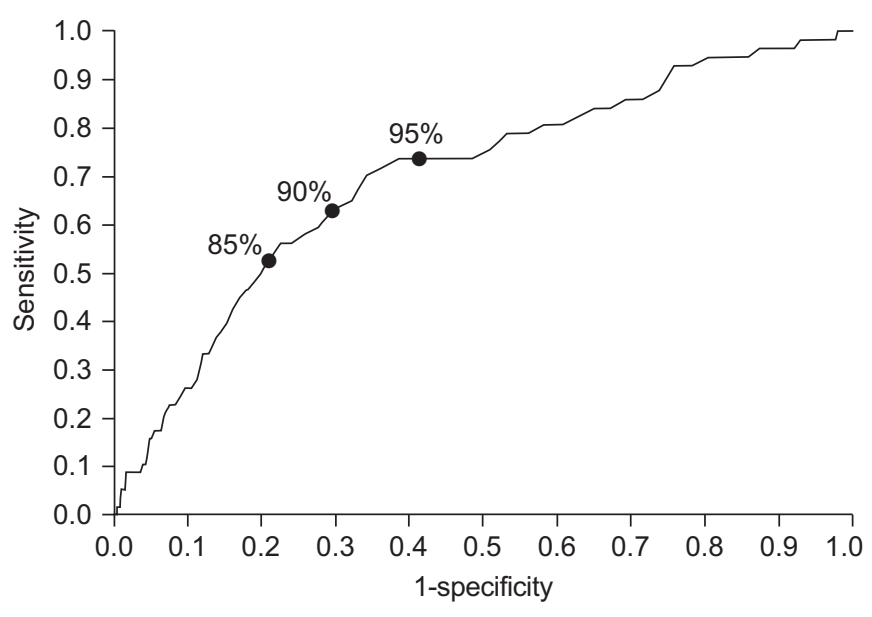

FIGURE 1. Receiver operating characteristic curve showing the cut-off level of forced expiratory volume in $1 \mathrm{~s} \%$ predicted with the best sensitivity and specificity for estimation of the odds ratio of lung cancer.

developing lung cancer. In particular, it shows that a reduction of as little as $10 \%$ of FEV $1 \%$ pred, is associated with an almost three-fold greater lung cancer risk. The corresponding attributable risk of lung cancer was 37.3\% (95\% CI 15.1-59.6). Despite the fact that functional alterations indicative of COPD were not associated with lung cancer risk, the present findings provided strong evidence that minimal and moderate functional impairment confers an increased risk of lung cancer, and a high attributable risk. This excess of risk was observed even in subjects not reporting functional alterations indicative of COPD.

The FEV1 index is a measure of airflow impairment that varies with age, height and sex. The standardisation of FEV1 \% pred has been adopted to adjust for these covariates and other kinds of standardisation have also been proposed [17]. In our data, FEV1/height ${ }^{2}$ and $\mathrm{FEV} 1 /$ height $^{3}$ gave similar risk estimates, but showed lower values in terms of the estimated area under the ROC curve. Moreover, the variation of FEV1/FVC ratio, with the adoption of different threshold for subsequent age groups, did not modify the results.

Several studies reviewed epidemiological evidence on the relationship between inflammatory pulmonary diseases, such as asthma and chronic obstructive diseases, and the risk of lung cancer. Research relating asthma and cancer did not reveal a consistent pattern of association, while the relationship between smoking, airflow obstruction and lung cancer is well recognised [19-24]. Cigarette smoking is the leading cause of lung cancer and is also the main cause of lung function impairment. Diseases characterised by airflow obstruction are associated with an increased risk of lung cancer. The results of our study are in agreement with those from a meta-analysis of population based prospective studies with $\geqslant 5,000$ participants, adjusting for smoking status [25]. WASSWA-KINTU et al. [25] reported that the reduction of lung function was an independent risk factor for lung cancer even for small differences in FEV1 \% pred, and the association was stronger for females than for males. The pooled relative risk for FEV1 \% pred in the first quintile $(<70 \%)$ compared with the fifth quintile $(\geqslant 100 \%)$ was 2.23 in males and 3.97 in females, respectively, but even relatively small decrements of FEV1 \% pred $(<90 \%)$ increased the risk of lung cancer, the pooled relative risk being 1.30 in males and 2.64 in females.

Subsequent studies confirmed this association. In a cohort study from Sweden based on 834 incident cases of lung cancer, PURDUE et al. [26] described the presence of obstructive lung

TABLE 3 Distribution of 57 cases of lung cancer and 3,749 controls for forced expiratory volume in $1 \mathrm{~s}$ (FEV1) \% predicted (pred) levels and corresponding ORs with $95 \% \mathrm{Cls}$ in strata of sex and smoking status and according to type of cancer for tumour, node, metastasis (TNM) classification and histology

\begin{tabular}{|c|c|c|c|c|c|}
\hline & \multicolumn{2}{|c|}{ FEV $1 \geqslant 90 \%$ pred } & \multicolumn{3}{|c|}{ FEV1 $<90 \%$ pred } \\
\hline & Cases/controls n & OR & Cases/controls n & OR $(95 \% \mathrm{Cl})^{\#}$ & OR $(95 \% \mathrm{Cl})$ \\
\hline Male & $17 / 1766$ & 1 & $28 / 786$ & $2.73(1.45-5.13)$ & $2.24(1.17-4.28)$ \\
\hline Female & $4 / 874$ & 1 & $8 / 321$ & $4.04(1.18-13.77)$ & $4.51(1.25-16.26)$ \\
\hline Former smokers & $3 / 695$ & 1 & $7 / 254$ & $5.77(1.43-23.2)$ & $4.55(1.11-18.7)$ \\
\hline \multicolumn{6}{|l|}{ TNM classification ${ }^{\S, f}$} \\
\hline Stage I & $15 / 2640$ & 1 & $21 / 1107$ & $2.54(1.28-5.05)$ & $2.23(1.11-4.47)$ \\
\hline Stage II-III-IV & $6 / 2640$ & 1 & $13 / 1107$ & 3.49 (1.28-9.53) & $2.45(0.88-6.84)$ \\
\hline \multicolumn{6}{|l|}{ Histology $y^{\S, f}$} \\
\hline Adenocarcinomaa & $19 / 2640$ & 1 & 20/1107 & $1.79(0.928-3.44)$ & $1.46(0.75-2.84)$ \\
\hline
\end{tabular}


disease as a significant predictor of incident lung cancer, and reported relative risks of 1.5 and 2.2, for mild and moderate/ severe COPD, respectively. In a case-control study based on 24 lung cancer cases, KISHI et al. [2] reported that airflow obstruction, but not emphysema extent on CT, was associated with higher risk for lung cancer. In a prospective study on a lung cancer screening population, DE TORRES et al. [27] found that the presence of emphysema, but not obstruction was associated with increased frequency of lung cancer. However, a study based on 99 cases of lung cancer reported a two-fold increased in risk of lung cancer for subjects with mild, moderate or severe airflow obstruction (GOLD stage I-IV) compared with those without airflow obstruction, and showed that both emphysema and airflow obstruction were related to lung cancer risk [28]. Thereby, data in the literature are still controversial, and further studies are required to clarify the relative importance of emphysema versus bronchial obstruction in lung cancer carcinogenesis.

Our study population is larger (3,869 subjects) compared with studies by WILSON et al. [28] (3,638 subjects), KISHI et al. [2] (1,520 subjects), and DE TORRES et al. [27] (1,166 subjects) and includes a higher number of lung cancer cases (57 cases) compared with KISHI et al. [2] (24 cases) and DE TORRES et al. [27] (23 cases). Our results underline the importance of baseline pulmonary function tests in lung cancer screening trials, indicating that even a modest reduction of FEV1 \% pred in smokers without COPD is predictive of an increased risk of lung cancer. Although our study is not comparable with previous studies that analysed the emphysema extent on CT, our preliminary findings, using dedicated software on 16-slice CT images, suggest that emphysema is not an independent risk factor for lung cancer [29].

The decrement in the levels of FEV1 \% pred has also been associated with the risk of cancer at sites other than the lung in an epidemiological study from Japan based on 34 cancer cases that reported a relative risk of 2.32 for COPD patients compared with patients with benign respiratory disease [30].

There are several possible explanations for the relationship between pulmonary function and lung cancer. In fact, it is well recognised that the extent of inflammation, fibrosis and luminal exudates in small airways are correlated with accelerated decline in FEV1. Airflow obstruction in smokers can be considered as a surrogate marker of significant carcinogenic exposure of the airways to cigarette smoke, as its effects persist even after separate and accurate allowance for dose and duration of smoking. Airflow limitation may be due to carcinogenic damage at a cellular level in susceptible subjects. Molecules of the stress response and cell death can activate the same receptors triggered by pathogens and contribute to tissue inflammation. Chronic inflammation, characterised by accumulation of inflammatory mucous exudates in the lumens, causes remodelling and thickening of bronchiolar wall associated with impaired tissue repair, whose imbalance might provide several growth factors fostering the growth of sporadically transformed cells. The individual response to inflammatory stimuli, polymorphism in Toll-like receptor and interferon regulatory factor genes, as well as of other inflammatory genes, might help to explain some individual variation in inflammation-cancer transition [31-36].
The sub-group analysis by histological types showed a major difference in lung cancer risk, and confirmed previous reports suggesting a stronger association of lung function impairment with squamous cell carcinoma than with adenocarcinoma [37].

The present study therefore indicates the role of lung function tests, a noninvasive, low cost and very fast examination, to identify optimal candidates for early detection trials. Pulmonary function tests and assessment of FEV1 should be considered when constructing strategies for lung cancer screening, in order to improve selection criteria. In fact, the frequency of benign lesions with last generation multi-slice CT is $\geqslant 50$ times higher than lung cancer detection rate $(<1 \%$ per yr) [38-40]. As a consequence, very large numbers of subjects have to be recruited in early lung cancer detection programmes, with a high chance of false-positive results, elevated costs and potential morbidity for the screened population.

In conclusion, defining reliable criteria for the assessment of a higher individual risk of lung cancer in heavy smokers might improve future prevention strategies, early detection approaches and clinical management of such a lethal disease. Airflow obstruction as surrogate marker for carcinogenic damage of the airways may be better than pack-yrs alone in predicting risk and can be used to select subjects for screening programmes. Moreover, the recognition of minimal lung function impairment, in individuals with otherwise normal CT scan features, could motivate smoking cessation with potential benefit in the overall mortality and public health care.

\section{SUPPORT STATEMENT}

The present study was supported by a Research Grant from the Italian Ministry of Health (Ricerca Finalizzata; Rome, Italy), the Italian Association for Cancer Research (AIRC; Milan, Italy), the Fondazione Cariplo (Milan, Italy) and the Lombardy Region.

\section{STATEMENT OF INTEREST}

None declared.

\section{ACKNOWLEDGEMENTS}

We would like to thank the volunteers, the radiological and laboratory technicians and the MILD project staff.

\section{REFERENCES}

1 Petty TL. Are COPD and lung cancer two manifestations of the same disease? Chest 2005; 128: 1895-1897.

2 Kishi K, Gurney JW, Schroeder DR, et al. The correlation of emphysema or airway obstruction with the risk of lung cancer: a matched case-controlled study. Eur Respir J 2002; 19: 1093-1098.

3 Nomura A, Stemmermann GN, Chyou PH, et al. Prospective study of pulmonary function and lung cancer. Am Rev Respir Dis 1991; 144: 307-311.

4 Skillrud DM, Offord KP, Miller RD. Higher risk of lung cancer in chronic obstructive pulmonary disease. A prospective, matched, controlled study. Ann Intern Med 1986; 105: 503-507.

5 Van den Eeden SK, Friedman GD. Forced expiratory volume (1 second) and lung cancer incidence and mortality. Epidemiology 1992; 3: 253-257.

6 Mannino DM, Aguayo SM, Petty TL, et al. Low lung function and incident lung cancer in the United States: data from the first National Health and Nutrition Examination Survey follow-up. Arch Intern Med 2003; 163: 1475-1480. 
7 Kuller LH, Ockene J, Meilahn E, et al. Relation of forced expiratory volume in one second (FEV1) to lung cancer mortality in the Multiple Risk Factor Intervention Trial (MRFIT). Am J Epidemiol 1990; 132: 265-274.

8 Young RP, Hopkins R, Eaton TE. Forced expiratory volume in one second: not just a lung function test but a marker of premature death from all causes. Eur Respir J 2007; 30: 616-622.

9 Pastorino U, Bellomi M, Landoni C, et al. Early lung-cancer detection with spiral CT and positron emission tomography in heavy smokers: 2-year results. Lancet 2003; 362: 593-597.

10 Brusasco V, Crapo R, Viegi G, et al. Coming together: the ATS/ERS consensus on clinical pulmonary function testing. Eur Respir J 2005; $26: 1-2$.

11 Global Strategy for the Diagnosis, Management and Prevention of COPD, Global Initiative for Chronic Obstruction Lung Disease (GOLD). www.goldcopd.org Date last accessed: October 14, 2009.

12 Swanney MP, Ruppel G, Enright PL, et al. Using the lower limit of normal for the FEV1/FVC ratio reduces the misclassification of airway obstruction. Thorax 2008; 63: 1046-1051.

13 Cerveri I, Corsico AG, Accordini S, et al. Underestimation of airflow obstruction among young adults using FEV1/FVC $<70 \%$ as a fixed cut-off: a longitudinal evaluation of clinical and functional outcomes. Thorax 2008; 63: 1040-1045.

14 Pellegrino R, Viegi G, Brusasco V, et al. Interpretative strategies for lung function tests. Eur Respir J 2005; 26: 948-968.

15 Breslow N, Day N. Statistical Methods in Cancer Research: Volume 1 - The Analysis of Case-Control Studies, International Agency for Research on Cancer. Lyon, Scientific Publications, 1980.

16 Doll R, Peto R. Cigarette smoking and bronchial carcinoma: dose and time relationships among regular smokers and lifelong nonsmokers. J Epidemiol Community Health 1978; 32: 303-313.

17 Miller MR, Pedersen OF, Lange $\mathrm{P}$, et al. Improved survival prediction from lung function data in a large population sample. Respir Med 2009; 103: 442-448.

18 Bruzzi P, Green SB, Byar DP, et al. Estimating the population attributable risk for multiple risk factors using case-control data. Am J Epidemiol 1985; 122: 904-914.

19 Ramanakumar AV, Parent ME, Menzies D, et al. Risk of lung cancer following nonmalignant respiratory conditions: evidence from two case-control studies in Montreal, Canada. Lung Cancer 2006; 53: 5-12.

20 Gorlova OY, Zhang Y, Schabath MB, et al. Never smokers and lung cancer risk: a case-control study of epidemiological factors. Int J Cancer 2006; 118: 1798-1804.

21 Bellia V, Pedone C, Catalano F, et al. Asthma in the elderly: mortality rate and associated risk factors for mortality. Chest 2007; 132: 1175-1182.

22 Santillan AA, Camargo CA Jr, Colditz GA. A meta-analysis of asthma and risk of lung cancer (United States). Cancer Causes Control 2003; 14: 327-334.
23 González-Pérez A, Fernández-Vidaurre C, Rueda A, et al. Cancer incidence in a general population of asthma patients. Pharmacoepidemiol Drug Saf 2006; 15: 131-138.

24 Brown DW, Young KE, Anda RF, et al. Asthma and risk of death from lung cancer: NHANES II Mortality Study. J Asthma 2005; 42: $597-600$

25 Wasswa-Kintu S, Gan WQ, Man SF, et al. Relationship between reduced forced expiratory volume in one second and the risk of lung cancer: a systematic review and meta-analysis. Thorax 2005; 60: 570-575.

26 Purdue MP, Gold L, Järvholm B, et al. Impaired lung function and lung cancer incidence in a cohort of Swedish construction workers. Thorax 2007; 62: 51-56.

27 de Torres JP, Bastarrika G, Wisnivesky JP, et al. Assessing the relationship between lung cancer risk and emphysema detected on low-dose CT of the chest. Chest 2007; 132: 1932-1938.

28 Wilson DO, Weissfeld JL, Balkan A, et al. Association of radiographic emphysema and airflow obstruction with lung cancer. Am J Respir Crit Care Med 2008; 178: 738-744.

29 Bellia V, Pedone C, Catalano F, et al. Asthma in the elderly: mortality rate and associated risk factors for martality. Chest 2007; 132: $1175-1182$

30 Nakayama M, Satoh H, Sekizawa K. Risk of cancers in COPD patients. Chest 2003; 123: 1775.

31 Hogg JC, Chu F, Utokaparch S, et al. The nature of small-airway obstruction in chronic obstructive pulmonary disease. $N$ Engl $J$ Med 2004; 350: 2645-2653.

32 Cosio M, Ghezzo H, Hogg JC, et al. The relations between structural changes in small airways and pulmonary-function tests. N Engl J Med 1978; 298: 1277-1281.

33 Ballaz S, Mulshine JL. The potential contributions of chronic inflammation to lung carcinogenesis. Clin Lung Cancer 2003; 5: 46-62.

34 Barnes PJ, Shapiro SD, Pauwels RA. Chronic obstructive pulmonary disease: molecular and cellular mechanisms. Eur Respir J 2003; 22: 672-688.

35 Ames BN, Shigenaga MK, Gold LS. DNA lesions, inducible DNA repair, and cell division: three key factors in mutagenesis and carcinogenesis. Environ Health Perspect 1993; 101: Suppl. 5, 35-44.

36 Wodrich W, Volm M. Overexpression of oncoproteins in nonsmall cell lung carcinomas of smokers. Carcinogenesis 1993; 14: 1121-1124.

37 Papi A, Casoni G, Caramori G, et al. COPD increases the risk of squamous histological subtype in smokers who develop non-small cell lung carcinoma. Thorax 2004; 59: 679-681.

38 Bach PB, Jett JR, Pastorino U, et al. Computed tomography screening and lung cancer outcomes. JAMA 2007; 297: 953-961.

39 Pastorino U. Early detection of lung cancer. Respiration 2006; 73: 5-13.

40 Pastorino U. Does screening for stage I lung cancer improve survival in a high-risk population? Nat Clin Pract Oncol 2007; 4: 218-219. 